\title{
ECOSYSTEM AND LANDSCAPES - A CRITICAL COMPARATIVE APPRAISAL
}

\author{
ZEV NAVEH \\ Faculty of Civil and Environmental Engineering, Technion, Israel Institute of Technology, \\ Haifa 3200 Israel.Email znave@technion.ac.il
}

Received: $26^{\text {th }}$ March 2010, Accepted: $28^{\text {th }}$ June 2010

\begin{abstract}
Ecosystems and landscapes are the two major spatial units for ecological research and practice, but their definitions and meanings are vague and ambiguous. Examining critically the meaning and complexity of both terms from a holistic landscape ecological systems view, the confusing applications of the ecosystem concept could be avoided by conceiving ecosystems as functional interacting systems, characterized for the flow of energy, matter and information between organisms and their abiotic environment. As functional systems they are intangible with vaguely defined borders. On the other hand, landscapes should be recognized as tangible, spatially and temporally well defined ecological systems of closely interwoven natural and cultural entities of the Total Human Ecosystem. Ranging from the smallest discernable landscape cell or ecotope to the global ecosphere, they serve as the spatial and functional matrix and living space for all organisms, including humans, their populations and their ecosystems. Both are medium-numbered complex ecological systems. However, the organized complexity of ecosystems is based solely on the monodimensional complexity of material processes of flow of energy/matter and biophysical information. But the organized complexity of landscapes is multidimensional and multifunctional, dealing not only with the functional dimensions of natural bio-ecological processes and the natural biophysical information, but also with the cognitive mental and perceptual dimensions, transmitted by cultural information and expressed in the closely interwoven natural and cultural landscape.
\end{abstract}

Key words: Holistic landscape ecology; ecosystem ecology; transdisciplinarity; ecological complexity; medium numbered systems

\section{INTRODUCTION}

Ecosystems and landscapes are used as the two major spatial units for ecological research and practice. Although they represent different conceptual approaches, their distinct meaning remains vague. Therefore both terms are used interchangeably and in ambiguous ways by many ecologists, land planners and managers, conservationists and restorationists. To rectify this situation my intention is to examine critically the epistemological and conceptual development of the ecosystem term as compared to the landscape term, their meaning and complexity and to offer alternative ways for their definition and application, based on a holistic landscape ecological systems view. 


\section{AMBIGUITY IN THE MEANING AND APPLICATION OF THE ECOSYSTEM CONCEPT}

To enable a proper comparison of both concepts we have to define first what we mean by these terms. Here we are already confronted with a major problem because of the ambiguousness in the definition of the term ecosystem, and the methodological deficiencies in its application in research and practice. It is outside the scope of this paper to discuss critically the voluminous literature dealing with the ecosystem concept and its application. This has been done more recently in an insightful way by Haber (2004), who has, rightly emphasized its great importance and value for the development of contemporary ecology.

We have discussed the ambiguity of the ecosystem concept and its role in the ecological hierarchy of integration above organism in more detail in our book on theory and applications of landscape ecology (Naveh and Lieberman, 1994). We raised the question if ecosystems can truly be regarded a "real" above-organismic, tangible phenomena, or are they not just conceptual tools for studying the flow of energy, material and information in ecological systems or are they both, as claimed by Schultz (1964) in a penetrating essay.

E.P. Odum (1971, page 8), who can be rightly recognized as the "American Father of Ecosystem Ecology", has defined ecosystems in the now classical book on the fundamentals of ecology as follows:

"Any unit that includes all of the organisms (i.e. the "community") in a given area interacting with the physical environment, so that the flow of energy leads to clearly defined trophic structure, biotic diversity and material cycles (i.e. exchange of materials between living and nonliving parts) within the system is an ecological system or an ecosystem".

In this definition we can find already the roots of confusion caused by interchanging organisms with community, without clearly defining what is meant by the "organisms" (also humans?) and what is the "community"?

In one of his more recent, important monographs (Odum, 1993, page 26), he used a much simpler and more "down to earth" definition for ecosystems, but it still leaves the vagueness of the highly controversial community concept open for discussion:

"The community and the nonliving environment function together as an ecological system or ecosystem".

In his model of the hierarchy of nature in this volume Odum (1993) presented for the first time also landscapes, occupying a higher level of organization above ecosystems, He called this level "ecosystems along with human artifacts". However, he did not clarify whether this hierarchy was meant as a spatial organization and ramification of ecosystems, or that any ecosystem with human artifacts should be considered a landscape with emerging qualities and additional complexity.

Another prominent American ecologist, R.O. Whittaker, did not bother much about semantic or epistemological problems. In his opinion the then ongoing disputes about the true meaning of communities, as opposed to ecosystems, were fruitless and 
counterproductive for the advancement of the science of ecology (Whittaker, personal communication, 1973). Therefore he applied an empirical approach and in his view an oak forest or patch of desert can be approached either as a community, in which productivity, diversity, and the like can be determined, or as a ecosystem in which energy/material cycling is studied (Whittaker, 1975).

Most other ecosystem definitions emphasize its holistic nature as interacting systems between living organisms and their non-living environment. However, a closer inspection of some of the most influential theoretical and practical ecosystem investigations indicate that in ecosystem research, the structural and functional interaction boils down actually into a functional approach with a more reductionistic than holistic inclination. This was the case already with the classical study by Lindeman (1942), a milestone in the development of ecosystem research. He was the first ecologist to apply the ecosystem concept in his study of the trophic structure and energy flow as "a trophic-dynamic approach" in a small and shallow lake with well-defined boundaries. Therefore he was able to study the whole lake ecosystem as a well-defined spatial unit with distinct borders. This would, however, not been the case if he would have to carry out this research in a larger aquatic system.

A strictly functional approach, measuring these physical-chemical and biological ecosystem processes was applied also in the "Solling Project" in North Germany. This was one of the most comprehensive and successful forest and grassland ecosystem studies within the International Biological Program. It was carried out by great number scientists from relevant natural sciences under the direction of the most influential German ecologist, Heinz Ellenberg (1971). He had great difficulties in coordinating and publishing the results of all these diverse measurements and bringing them under the common roof of the "Solling ecosystem". The reason was that this "whole ecosystem study" has been carried out in the typical multidisciplinary manner of isolated studies, lacking the integration and cooperation of inter- or trans-disciplinary studies (Ellenberg, 1970, personal communication).

\section{Ellenberg (1973) defined the ecosystem, as}

"An interacting system, formed by living organisms and their abiotic environment". He regarded the ecosystem concept as "rankles", being applied both to the abstract system type and the concrete space-time systems. Ellenberg realized very well the dichotomic position of humans, acting as a "supernatural factors" both inside and outside the ecosystem. However, for their actual classification he recognized ecosystems as functional units, making a clear distinction between natural and close-to-natural and artificial urban industrial ecosystems. As discussed in detail by Naveh and Lieberman (1994), his approach inspired our distinction between solar-energy powered biosphere landscapes and fossil and nuclear-energy powered technosphere landscapes.

A typical functional ecosystem approach was applied also by Likens et al. (1977) in their classical long-term North American study of the Hubbard Brook "forested ecosystem", measuring nutrient inputs and outputs and the biochemistry of different watershed landscape units within the larger experimental forest sites. However, in the discussion of their results, the researchers called rather indiscriminately these watersheds and study sites sometimes ecosystems and sometimes also landscapes. 
In a thorough theoretical study of ecosystem complexity and its formalization, Jorgensen (1997) based his holistic approach chiefly on principles of thermodynamics and recent insights into self-organization of dissipative structures. He presented ecosystem networks relations that deal with different cycling functions, driven by energy. They are therefore typical functional ecosystem models. The only actual examples of ecosystem studies as spatial units are derived from well-delineated aquatic systems, such as lakes and rivers. However, if the inputs and outputs from bordering terrestrial ecosystems and their resulting land-water ecotones interactions would have been taken into account, then even in this case, their functional boundaries would become fuzzy.

Attempting the integration of the contrasting views of ecosystems, regarded either as biotic assemblages or as functional systems, Jorgensen \& Muller (2000 page 10), defined ecosystems

"As both biotic and functional system, able to sustain life and including all biological variables. Their spatial and temporal scale are not specified a priori, but entirely based upon the objects of the ecosystem study".

In a similar vain, Noss (2001, page 105), recognizing, rightly the practical meaning of ecosystems as functional system with spatially undefined boundaries, defined ecosystems for the sake of the practicing conservationists and land managers, simply as:

"Open systems, exchanging matter, energy, and organisms among them. Where to draw the lines between them appears largely arbitrary."

Although using the common term "ecosystem management" in some of his models, in this study, Noss (2001) devoted his discussion and practical conclusions on conservation entirely to landscapes and eco-regions (which are actually, landscapes on broader regional scales).

One of the most recent definitions of ecosystem is by De Leo and Levin (2000):

"Ecosystems are not notuniquely identified entities nor are they defined by sharp boundaries. Instead they are loosely defined assemblages that exhibit characteristic patterns over a range of scales of time and space and organization complexity".

To this definition the American environmental philosopher Sagoff (2000, page 69) responded in a critical essay of ecological theories:

"The oxymoron 'loosely defined' may be taken as a euphemism for undefined or constructed in silico (on a computer) to illustrate or vindicate a particular theory."

It is very significant that in a comprehensive collection of studies by Cadenasso et al., (2003), proposing conceptual and methodological tools to advance the integrated study of the structure and functions ecological boundaries, the focus was naturally on landscape systems at different scales and not on ecosystems. The term "ecosystems" was not mentioned at all by Cadenasso and his colleagues. 


\section{CRITICAL APPROACHES TO THE ECOSYSTEM CONCEPT AND ITS "NATURAL ECOSYSTEM" PARADIGM}

O'Neill et al. (1986) made a widely cited attempt to improve the weaknesses of the ecosystem concept, being "diffuse and ambiguous", and tried to resolve the conflicting biological and functional ecosystem approaches by a proper hierarchical system approach. 15 years later, O'Neill (2001) outlined in an even more critical way the severe limitations of the ecosystem paradigm. In this prestigious Robert H. Mac Arthur Award Lecture, he even raised the question whether it is not time "to bury the ecosystem concept" altogether. $\mathrm{He}$ maintained that the spatial dimensions of the ecosystem pose two serious problems: Firstly, the implicit assumption that interactions and feedback loops necessary and sufficient to explain dynamics, occur within the ecosystem boundaries, while in fact the spatial distributions of component populations may be much larger. Secondly, spatial homogeneity within the ecosystem is typically assumed. This simplification overlooks some of the essential properties of the system: it is the heterogeneity of the system that maintains the full range of populations within the system. Another crucial limitation of the ecosystem paradigm is that it typically considers human activities as external disturbance.

According to O'Neil (2001), a major argument is that the ecosystem concept is based on the "machine analogy" inherent in system analysis, implying an outdated homeostatic balance of nature view". The ecosystem is not an a posteriori, empirical observation about nature, but an a priori paradigm of a specific way of looking at nature, emphasizing some of its properties while ignoring and de-emphasizing others. Among those neglected are Homo sapiens, moving ecological systems outside conditions that have existed over evolutionary history. "Homo sapiens is not outside the system".

In fact, apparently many ecologists seem to have overlooked that already Tansley (1935) in his seminal paper in which he introduced the term "ecosystem", he regarded humans as a major agent of change and as an integral part of the ecosystem concept. However, they cling to the "natural ecosystem" paradigm, by which humans are considered as unwanted and disturbing external ecosystem agents, distorting nature's harmony by deflecting the climax. Therefore most of those ecologists who adopted Tansley's ecosystem term, continued to consider the "natural ecosystem" devoid of humans as their principle object of study.

This is true also for ecosystem ecologist, claiming to have a holistic ecosystem conception: Thus, for instance, only in the third edition of his very influential "Fundamentals of Ecology" text book, Odum (1971) paid any attention to humans as an ecological factor. But even here, in the major part of this volume he dealt almost exclusively with natural ecosystems, their biotic communities and the abiotic environment, developing towards a "mature" homeostatic climax stage without human interference. Natural ecosystems were conceived by him as the basic functional unit in nature and as the highest level in the ecological hierarchy. Only in the last chapter on applications and technology as applied human ecology, he considered human dimensions in ecosystems. However, much later in his above mentioned book on ecology and the endangered lifesupport systems he recognized humans as part of "urban-industrialized" ecosystems (Odum, 1993).

Also Joergensen (1997) in the above mentioned study restricted his "integration of ecological theories" solely to the biological-ecological and chemo-physical dimensions. He 
treated ecosystems as if they are all natural ecosystems, devoid of humans and the resulting human ecological dimensions. Such a general trend of emphasis on biological, chemical, and physical elements, omitting human-cultural elements, is also obvious in almost all prominent ecosystem studies, such as Connell et. al. (1987); Noy-Meir (1975); Pacala et al. (1993) Picket and White (1985).

As we can learn from the evolution and history of the Mediterranean landscape humans played an important role in shaping this landscape already from the Pleistocene onwards (Naveh 1971; Naveh, 1984; Naveh, 2007; Naveh and Lieberman, 1994; Naveh and Carmel, 2003) All untillable Mediterranean upland ecosystems have been exposed to human activities for very long periods, first in the Pleistocene in by Paleolithic human habitation, fire, hunting, food gathering, and in the Holocene by grazing and browsing of domestic livestock, woodcutting, brush clearing and cultivation. This caused the extinction of big mammals - herbivores and most of their predators, the loss of taller trees, the erosion of the upper profile and the impairment of watersheds, and, finally the overall desiccation. However, at the same time the homeostatic primeval "climax" forests have been turned into homeorhetic, human-degraded and converted upland ecosystems of sclerophyll woodland, shrubland, savannas and derived grasslands. In these agro-pastoral semi-natural and cultural landscapes fire, humans and their habitations sites, their ax and livestock have become inseparable and integral parts of the Mediterranean ecosystems. Therefore, the total exclusion of human interventions cannot be regarded as creating a "natural ecosystem" situation, leading to a preconceived, hypothetical climax, as postulated by Braun-Blanquet, but to dense species - poor Maquis brush thickets.

Also Alberti and colleagues (2003), have shown recently in a thorough review that in spite of the fact, that there is not a single extensive ecosystem left on Earth which has not been influenced and modified to lesser or greater degrees by humans, this "natural ecosystem" paradigm is still popular today. However, even when humans are recognized in "the new paradigm" as components of ecosystem, the attempts to understand humandominated systems remain reductionistic and human ecological processes are treated almost exclusively as separate phenomena. This was also apparent, with few exceptions, in most of the contributions to the anthology edited by Mc Donnell and Pickett (1993).

At the same time, however, a clear tendency can be noted among ecologists, rejecting this narrow bio-ecological natural ecosystem paradigm. This is reflected in the widely distributed online Journal "Ecology and Society", (formerly called "Conservation Ecology"), promoting ecological and human systems integration (Holling, 2000). In the same vain, attempts are made in a recent collection of essays to develop an integrative theory of transformations in natural and human systems from the angle of resilience and adaptive cyclic changes (Gunderson and Holling, 2002). Serious efforts are also made for an integration of humans into urban ecosystems both in Europe (Breuste, et. al., 1998) and in the United States (Alberti et al., 2003).

\section{CRITICAL APPRAISAL OF THE MEANING OF LANDSCAPES}

The evolution of the landscape term has a long and exciting history, but it is outside the scope of this review to present a detailed overview of the changes its meanings that it has undergone throughout history. It was first mentioned in the Bible, in the Book of Psalms (48.2) as the beautiful overall view of Jerusalem, with King Salomon's temple, castles, and palaces. This original visual-perceptual and aesthetic connotation has been adopted in 
literature and art, and is still used chiefly by those involved in landscape architecture and designing, and by gardeners. However, since the Renaissance it has acquired gradually a more inclusive meaning by which the landscape is perceived both as a tangible spatialvisual reality and as an intangible, mental, spiritual and artistic experience (Naveh and Lieberman, 1994).

The scientific-geographic term landscape was introduced in the early 19th century by A. von Humboldt as 'Der Totalcharacter einer Erdgegend" (The total character of an Earth region"). Later-on geographers have narrowed the landscape term down to the characterization of the physiographic, geological, and geomorphologic features of the earth's crust. The prominent German biogeographer Troll, who coined the term "landscape ecology", already in 1939, has also given to "landscapes" a broader, holistic interpretation, defining it as:

" The total spatial and visual entity of human living space, integrating the geosphere with the biosphere and its noospheric man-made artifacts, a fully integrated holistic entity, meaning a "whole" that is more than the sum of its parts and that should, therefore be studied in its totality (Troll, 1971).

As we have described in more detail (Naveh and Lieberman, 1994), landscape ecology emerged after World War II in the industrialized countries of Central Europe as an interdisciplinary science of landscape planning, design, management, conservation, and restoration. Most European landscape ecologists have accepted, in principle, this holistic definition of landscape, but have given it diverse interpretation in their landscape ecological studies.

More recently, the development and perspectives of European- and chiefly German landscape ecology has been presented by Bastian and Steinhardt and their colleagues (Bastian and Steinhardt, 2002) in what can be regarded as the one of the most comprehensive compilation on landscape science in general. Although focusing chiefly in Europe, the conceptual and methodological contentions of this important anthology have opened new vistas for all those on all continents, who are ready to accept new ideas, enriching and improving their own work and teaching. This is true especially for all those, who are exposed mainly to the publications on landscape ecology in the English language, without having the opportunity to get acquainted with this rich source of knowledge and information.

Following these landscape ecologists in Central Europe, we have adopted this holistic connotation, embracing both the biophysical and humanistic perspective. However, we have included in the "total human living space" of landscapes not only the three dimensions - of the tangible physical space, but also the multidimensional, intangible mental space in which we live (Naveh and Lieberman, 1994; and Naveh, 2000). This will be further discussed in the next subchapter, dealing with the comparative complexity of ecosystem and landscapes.

An important epistemological and methodological contribution to the meaning and practical application of the holistic landscape concept was the introduction of the ecotope term as the basic unit for landscape study, with well defined chorological and topological dimensions. This term was coined already by Tansley (1935) and has been adopted by 
European landscape ecologists as the smallest, more or less homogenous and clearly discernible and mappable building block of nature with all its subordinated landscape elements and fluxes. These are mapped in scales from 1:10 000 or 25000 up to maximum 1: 50 000. The smallest ecotope scale can be enlarged into higher landscape units and these into larger land systems (Zonneveld, 1995; Bastian and Steinhardt, 2002). Thereby the ecotope has been defined by European landscape ecologists as a much more rigorous and explicit study unit for landscape ecological research than the patches and gaps terms, introduced by North American landscape ecologist.

In the early eighteenth of the last century, together with the emergence of landscape ecology in North America, as well as in the English-speaking world in general, the spatially oriented meaning of the landscape, as defined by Forman and Godron (1986, page 9, 11), was adopted:

"Landscapes are a heterogeneous land area composed of a cluster of interacting ecosystems that is repeated in similar form throughout. Landscapes vary in size down to a few kilometers in diameter."

This means in fact that landscapes are conceived as nothing more than a spatial ramification of interacting ecosystems on $\mathrm{km}$ wide scales. Without a clearer distinction between both terms of ecosystems and landscapes, this leaves open the question, how we can delineate the landscape, composed of such clusters of ecosystems, in case there are no clearly distinct geomorphologic, ecological or other boundaries? How many clusters are included in each landscape? Do these clusters of ecosystems include also roads, buildings, roads, farms, villages, and towns?

In his more recent, comprehensive monograph on landscape mosaics, Forman (1995 page 38) defined ecosystems simply as "Relatively homogenous areas of organisms interacting with their environment". However, he provided only examples of "local ecosystems" and referred to patches or corridors as "a matrix of a landscape". These definitions did not resolve the fuzziness of the ecosystem-landscape relations, typically for so many studies.

Unfortunately this coupling of ecosystems with the perception of landscapes, existing only on larger scales, has contributed much to the prevailing view that landscape ecology is nothing more than a spatial expansion of ecosystem ecology, studied on larger scales. This was already apparent by the definition of the prominent American ecologist Paul Risser (1987) stating that landscape ecology focuses on spatial heterogeneity, emphasizing ecological effects of the spatial patterning of ecosystems over large area of landscape mosaics.

As a result, landscape ecology has been ignored by many ecosystem ecologists and geographers, who believed that their conventional sciences can take care very well of such spatial ramifications and there is no need for creating a special, competing discipline for these larger-scale issues. Unfortunately, even now, after landscape ecology has matured and proofed itself as an important environmental worldwide science on its own right, many large scale and global ecological projects and biogeographic classifications are still conducted without being aware at all of the existence of landscape ecology and its advanced methods and models. One striking example is a worldwide pilot study, carried out jointly by 175 interdisciplinary scientists under the auspices of the United Nations 
Development Program and the United Nations Environment Program, the World Bank and the World Resources Institute (World Resources, 2000-2001).

However, also some European landscape ecologists have not resolved the vagueness of these ecosystem-landscape relations. Following the unfortunate tradition of German geographers by overloading their science with numerous terms with complex definitions, Leser (1997) introduced many more subdivisions of the ecotope term and created further confusion by introducing the "landscape ecosystem" as a further development of the ecosystem. (If the landscape is both a functional and structural ecological system in its own, then there is not need for adding "ecosystem"!) In a similar vein, Loeffler (2002) used many different terminological distinctions for "landscape complexes", and for their topological dimensions he mentioned "landscape complexes (ecosystems)", without further explaining what is meant by this addition, and why is it necessary at all.

The process of broadening the spatial-explicit dimensions for studying landscapes at regional and even global scales, the scopes of the original Central European conception of landscape ecology has also been broadened and enriched by the development of "quantitative spatial landscape ecology This version has been developed in North America and represented in a most comprehensive manner by Turner and colleagues (Turner et al. 2001), as well as and in many studies, published from 1986 onwards in the journal "Landscape Ecology". At the same time, the gradual, ongoing amalgamation of the different versions of landscape ecology into a broad, highly diverse and chiefly problemsolving oriented global science with clear inter-and transdisciplinary trends has taken place (Naveh and Lieberman, 1994; Wu and Hobbs 2002). This process has been energized by innovate conceptional, methodological and practical approaches of landscape architects and planners, foresters, conservationists and restorationists, who joined landscape ecologists with ecological and geographic academic background. As discussed in more detail in the last chapter of my Springer anthology (Naveh, 2007b), landscape ecologists are moving also more and more towards interdisciplinarity approaches, integrating their disciplinary knowledge from their various fields of expertise in landscape study, planning and management. Together with these developments a clear shift occurred, away from viewing humans apart from nature towards more holistic views of human-nature-landscape relations.

In his editorial, commemorating the 25th anniversary of IALE and the 20th anniversary of "Landscape Ecology" Wu (2007), pointed out, rightly, that IALE and the journal of Landscape Ecology will continue to play a pivotal role in advancing the science and practice of landscape ecology in decades to come as an interdisciplinary science, focusing on the ecology and sustainability of landscapes. In view of the present severe ecological crisis, our concluding statement of the place of landscape ecology in the scientific community (Naveh \& Lieberman, 1994) that "the health and integrity of landscapes are of vital importance for global survival", has now become the most urgent challenge for all landscape ecologists. 


\section{CLEARER DEFINITIONS FOR THE CONTRASTING MEANINGS OF ECOSYSTEM AND LANDSCAPE}

The ambiguity in definition and confusing applications of the ecosystem concept could be avoided by conceiving ecosystems as:

Functional interacting systems, characterized for the flow of energy, matter and information between organisms and their abiotic environment and a set of interlinked, different scale properties. As functional systems they are intangible with vaguely defined borders, lacking the two properties which have been recognized already by Aristotle as tangible things: these have to be occupying a certain (measurable) space ("Choros") in a well definable location ("Topos").

In spite of the different interpretations of the semantic and epistemological meaning of landscape, it can be safely assumed that in clear contrast to the vaguely defined ecosystems as a scientific object of study, landscapes are conceived by landscape ecologists as concrete pieces of land, or water or both, along different scales. However in contrast to the above-mentioned, mechanistic conception of landscapes as large-scale repeated ecosystem, we should recognize landscapes as tangible, spatially and temporally well defined ecological systems of closely interwoven natural and cultural entities of our living space. Ranging from the smallest discernable landscape cell or ecotope to the global ecosphere landscape of they serve as the spatial matrix and as the living space for all organisms, including humans, their populations and their ecosystems.

Rather similar conclusions have been reached by Allen and Hoekstra (1992) in their challenging critic of conventional concepts in ecology. They recognized these contrasting meanings of ecosystems as intangible, functional systems, defining them "as pathways of processes and fluxes between organisms and their environment" and concluding: (Allen and Hoekstra, 1992, page 125):

"The ecosystem criterion is very distinct from all others. Like communities, it bears a complex relationship to landscapes. For the most part it is unworkable and certainly depauperates the concept to think of an ecosystem as a place on a landscape." On the other hand they regarded landscapes, as" the tangible matrix for all organisms, at any scale".

\section{COMPARATIVE COMPLEXITY OF ECOSYSTEMS AND LANDSCAPES}

In recent years much attention has been devoted to ecological complexity and since 2004 the journal of "Ecological Complexity" has become a major platform for these studies. Rooted in General Systems Theory, ecological complexity has benefited greatly in its recent developments from the great advances in computerized system modeling and simulation, as well as from recent insight in self-organization, and the chaotic and coevolutionary processes in nature and human societies. However, it is rather regrettable that the great majority of these studies fail to include the human factor as an integrative part in their inquiries of ecological complexity and biocomplexity. This is not only true for ecosystem studies, like the important study by Jorgensen (1997) mentioned above, but even for studies, related to cultural landscapes. Thus, for instance (Cadenasso et al., 2006), in their detailed treatment of biocomplexity, distinguishing three dimensions of heterogeneity, connectivity, and history, deal only with the bio-physical dimension of ecosystem complexity. For this purpose they explore in depth only the axes of increasing 
organized complexity in the mono-dimensional spatially explicit heterogeneity of landscapes, applying spatial "patches" as their major research unit.

In their recent book on "Complexity in Landscape Ecology" Green and colleagues (Green et al., 2006) consider the strictly biological and ecological criteria of plants and animals in a very lucid way, but they ignore completely the complexity caused by the interactions of these organisms with humans. The authors seem not to be aware of (or ignore) the existence of a science of landscape ecology and the great body of landscape-ecological studies. These include also those, published in the same "Springer Landscape Series", whose editors aim to publish manuscripts "approaching landscapes from a broad perspective", and define landscapes as "home and livelihood for people, house, history, artefacts"..., "shaped and governed by human societies."

Before discussing the great differences of ecosystem and landscape complexity, let us consider first briefly their common features. According to the definition by Weinberg (1975), these are both "medium-numbered systems". He maintained that the complexity of systems is determined not only by the number of components, but also by the number of interactions and their nature - their "structural complexity", and by their "functional complexity", defined by the number and character of the distinct functions carried out by these system. As complex ecological interacting systems, both ecosystems and landscapes differ from "small numbered systems" that have only few components with simple causeeffect interactions, and can be described each by a single equation. In contrast to the disorganized complexity of "large numbered systems", such as gases, composed of many identical and randomly interacting and components, ecosystems and landscapes, have both organized complexity. They are essentially highly diverse "medium-numbered systems with structural and functional networks of biotic and abiotic interrelationships for which neither statistical and mechanistic approaches nor their description and analysis are sufficient. The greater this organized complexity, the greater its uncertainty and the lesser its predictability (Weinberg, 1975; Jorgensen, 1997). However, because of the much higher multifunctional and multidimensional organized complexity of landscape, their unpredictability is even greater. This higher functional and structural complexity and the resulting additional dimensions can be explained by the emergence of new systems qualities of landscapes as ordered whole or "Gestalt" systems in which, like in an organism (or a melody) all their parts are related and depending on each other by a unique level of coherence. Whereas the organized complexity of ecosystems is based solely on the monodimensional complexity of material processes of flow of energy/matter and biophysical information, the multifunctional organized complexity of landscapes is multidimensional. Here we deal not only with the functional and structural dimensions of natural- bio-ecological processes and the natural biophysical information, but also with the cognitive mental and perceptual dimensions, transmitted by cultural information and expressed in the closely interwoven natural and cultural landscape patterns.

This holistic view of landscape complexity presents therefore a special case of the coherence in nature and mind, by which natural bio-physical and cultural cognitive system events are integrated into a complex landscape system. This coherence is so correlated that what happens in one part of the system, happens to all other parts. This is the case, when we study, plan and manage landscapes with the dual, biperspectivable view, simultaneously as integrated natural cognitive and psychophysical systems (Naveh, 2001). 
The recognition of this multidimensional complexity is of special importance for integrative landscape appraisal, planning and management practices in human modified semi-natural and cultural landscapes, making out the overwhelming majority of all landscapes. In these, natural patterns and processes are closely interwoven with cultural ones, with emerging structural and functional complexity. As mentioned already, this is the case with Mediterranean landscapes, shaped by humans for hundred thousands of years. But it will be certainly apply also to other landscapes with a very long human history, like China. All these semi-natural landscapes with spontaneous developing and reproducing organisms should be regarded therefore as coherent natural + cultural, mediumnumbered ecological systems.

This view of multidimensional and multifunctional landscape complexity is embedded in the web of life in its totality. It has emerged from the recognition that humans are not apart from nature or even above nature. They form together with their total environment an indivisible and coherent co-evolutionary geo-bio-anthropological entity. We have called this social-ecological supersystem the Total Human Ecosystem (THE), and regard it as the highest level of the global ecological hierarchy, above the natural ecosystem level (Naveh, 1982; Naveh 2000; Naveh and Lieberman 1994).

\section{COMPREHENSION OF LANDSCAPE COMPLEXITY AS PART OF A TRANSDIS- CIPLINARY SYSTEMS VIEW OF THE WORLD}

As explained elsewhere in more detail (Naveh 2000), this holistic conception of landscape complexity cannot be considered in isolation but has to be part of a broader integrative system view of the world, rooted in General Systems Theory and its recent insights in self-organization and self-creation or autopoiesis. As part of the transdisciplinary scientific revolution - senso Kuhn (1970) - it is characterized by a major shift from reductionistic and mechanistic and linear scientific paradigms to an all embracing organic conception of cosmic, geological, biological and cultural evolution as a non-linear but coherent process (Jantsch, 1980; Laszlo, 1987). The scientific breakthrough achieved in non-equilibrium thermodynamics and its new ordering principles by the Nobel Prize winner Prigogine and his collaborators, "creating order through fluctuations and out of chaos" (Prigogine and Stengers, 1984), have deepened our understanding of the complex dynamics of these landscapes far from equilibrium and their capacity of continuous selforganization from lower to higher hierarchical levels. Mediterranean semi-natural "biosphere" landscapes behave apparently like dissipative structures, resulting from short-to long term cyclic perturbations of natural climatic fluctuations, and of human-induced long and short-term cultivating, grazing, browsing, cutting, and burning rotations. In seminatural Mediterranean landscapes, and most probably also in other human perturbation-dependent landscapes, these lead to the establishment of a human-maintained dynamic flow equilibrium - or "homeorhesis" between the tree, shrub, herb and grass layers, ensuring their high biological and ecological complexity and diversity (Naveh, 1998a).

According to Li (2000) these dynamics can now be explained in rigorously thermodynamic and formal terms. Li applied Prigogine's (1997) Self-organization Theory and Haken's (1987) "Synergistics", providing four fundamental principles governing these processes for the interpretation of landscape instability and multistability, as dissipative systems in which stochastic fluctuations lead to an intrinsic instability in landscapes, proofed by examples from northern Germany and Texas landscapes. 
The shift towards an all-embracing holistic paradigm is presently reaching its peak. It offers a unified view of the world, "which is perceived not anymore like a giant mechanism, but as cast organism, in which every part affects every other" (Laszlo 1994). To this unified view of the world Laszlo (2003; 2004) has contributed a genuine transdisciplinary theory for the "integration of everything". This has been achieved by summarizing, integrating and interpreting the latest findings in such diverse sciences as quantum physics, physical cosmology, evolutionary-, neuro, - and quantum biology, and in the new field of consciousness studies. He has laid thereby the foundations for an integral science of quantum, cosmos, life and consciousness, putting it on the cutting edge of the transdisciplinary scientific revolution and its post-modern complexity science.

These theories have also opened new vistas for our understanding of the complex reciprocal relations between human society and its landscapes. Their consequences have far-reaching implications for our holistic and transdisciplinary landscape concepts. They should become an integral part of a comprehensive conception of synthetic geological, biological and cultural landscape evolution. These issues are not only of greatest significance for the theoretical foundations of the new transdisciplinary landscape science. They will hopefully also provide conceptual, educational and practical tools for all those concerned with the sustainable future of nature and human life on Earth to attain the urgently needed post-industrial symbiosis between human society and nature Naveh, 2007b).

\section{CONCLUSIONS}

Among the most important practical consequences from this critical comparison between ecosystems and landscapes is the need for a much broader, integrative appraisal of their multidimensional landscape functions. Neither the formal languages, nor statistical approaches, nor their mechanical description and analysis as Archimedean geometrical configurations and mosaics, offered first by Forman (1986), can accurately grasp this multidimensional complexity. Our medium numbered natural + cultural landscapes cannot be investigated only with the help of maps and mathematical models. Their study requires the help of the natural language and its semantic and other visual expressions by innovative transdisciplinary approaches and methods (Naveh and Lieberman, 1994). They cannot be replaced, even by recent, impressive advances achieved at the interface of ecology and conservation, mathematics, statistics and computer science, such as discussed recently by Green et al. (2005). The above-mentioned biperspective landscape view enables their evaluation, not only in the anthropocentric dimension of "hard" instrumental and marketable values. It enables also the evaluation of the "soft" ecocentric, aesthetic and ethical dimensions. These are not dependent on utilitarian values but are grasped with our cognitive and perceptual dimensions and consciousness and can be evaluated with the help of our natural language.

This has been shown convincingly in transdisciplinary landscape studies, reported in a recent anthology of European rural landscapes, based on the $20^{\text {th }}$ session of the Permanent European Conference for the Study of Rural Landscapes (PECRL). In the words of the editors of the proceedings of this important conference (Palang et al., 2004, page 4):

"Language is not merely a means of communication. It allows for the construction, imagination and abstraction of the complex world around us using a powerful linkage 
between hidden meanings and power and real objects and features that we all can perceive in our environment.... Language allows us to tell narratives of places and landscapes, to transmit inherited values and knowledge."

To accept this linguistic expression as an important scientific tool we have first to overcome the deeply ingrained dualistic view of the positivistic natural sciences approach, teaching us that mental phenomena "do not count because they cannot be counted", or measured and quantified by statistical mathematical models and other means of our formal scientific language.

Ongoing exponential landscape degradation cannot be prevented by treating landscapes solely as a commodity to be exploited or as a resource on which we project our economic interest and measure by monetary parameters and products of the "free market play". We have to recognize the intrinsic values by which they become not a means to an end, but an end in themselves. Even the term " natural capital," introduced by ecological economists, cannot account fully for the most vital life-support functions provided by fertile soil, clean air, and water. Nor can this account at all for the intangible aesthetic, cultural, spiritual, and re-creative values of healthy and attractive biosphere landscapes. Especially, since their importance for our quality of life and mental well-being in the emerging information society is greater now than ever.

As explained in more detail by Naveh (1998b) and by Li (2001), we can achieve the goal of having precisely manipulative linguistic expressions for these qualitative, aesthetic, spiritual, historic values and other "soft" cultural parameters with the help of innovative statistical and modeling methods, based on fuzzy logic mathematics. The comprehension and application of this multidimensional and multifunctional landscape complexity is precondition for the preparation of strategies for integrated ecological, socio-economical and cultural sustainable development. It requires a common effort of landscape ecologists with scientists from relevant natural, social and human field as well as with artists, planners, architects and eco-psychologists, land use managers and decision makers. As shown by Grossman and Naveh (2000; and by Naveh (2007b), it can be achieved by systems dynamic models in combination with cross-catalytic networks, assessing the interrelations between anthropogenic process and landscape dynamics for regional sustainable development.

Important examples for the practical implementation of the evaluation of such multidimensional complexity by integrating ecological, socio-economic and aesthetic aspects in landscape planning and management, have been presented at the conference on "Our Shared Landscape" (Lange and Miller, 2005). Such integration was achieved by a biperspectivable view of ecological and aesthetic quality, by the application of fuzzy logic models, transdisciplinary systems simulation models and other interactive methods and tools.

One of the most urgent transdisciplinary challenges for this purpose is the development of practical tools for such integrated assessment of the closely connected biodiversity, cultural diversity and ecological macro-and micro-site heterogeneity by joint indices of "Total Landscape Eco-diversity" (TLE) that can be easily applied by land managers and users, and has been described in more detail in Naveh (1994; Naveh 1998a; 1998b) Such 
TLE indices are of special value for landscape conservation and restoration projects, and wherever both ecological and cultural assets are endangered.

Implementing these multifunctional and multidimensional landscape complexities, landscape ecologists, planners, conservationists and restorationists will be much better equipped to deal with semi-natural landscapes and to further help in the transformation of unsustainable agro-industrial landscapes with high-inputs and highthroughputs into sustainable, regenerative, non-polluting but no less productive agroecological landscapes. The same is also true for urban landscape planners and designers in the creation of healthier, more livable, and more attractive urban-industrial technosphere landscapes.

To achieve this goal of more sustainable post-industrial Total Human Landscape we will have to shift our focus from the rigid, geometric landscape structures and from theoretical exercises, preventing our comprehension of the complexity of dynamic landscape processes and functions. We will have to be ready to present our work, not only as strictly scientific publications, but also as well-illustrated, non-formal, and easily accessible "pragmatic" information, that can help changing reality through their feedback on decision makers and the public at large.

\section{REFERENCES}

Allen, T.H.F., Hoekstra, T.W. (1992). Toward a Unified Ecology. New York: Colombia University Press.

Alberti, M., Marzluff, J.M., Schulenberger, E., Bradley, G., Ryan, C. \& Craig, Z. (2003). Integrating humans into ecology: Opportunities and challenges for studying urban ecosystems. Bio-Science 53, 1169-1179.

Bastian, O., Steinhardt, U. (2002). Development and Perspectives of Landscape Ecology. Dodrecht: Kluwer Academic Publishers.

Breuste, J.H., Feldman, H. \& Uhlmann, O. (1998). Urban Ecology. Berlin, Heidelberg, New York: Springer.

Carmel, Y., Naveh, Z. (2002). The paradigm of landscape and the paradigm of ecosystems implications for landscape planning and management in the Mediterranean region. Journal of Mediterranean Ecology, 3, 35-46.

Cadenasso, M.L., Pickett, T.A., Weathers, K.C., Bell, S.S., Benning, T.I., Carreiro, M.M., \& Dawson, T.E. (2003). BioScience 53:717-722.

Cadenasso, M., Pickett, S.T.A., \& Grove, J.M. (2006). Dimensions of ecosystem complexity: Heterogeneity, connectivity, and history. Ecological Complexity 3:1-12.

Connell, J. H., Noble, I. R. \& Slatyer, R. O. (1987). On the mechanisms producing successional change. Oikos 50: 136-137.

De Leo, Levin, S.A. (1997). The multifaceted aspects of ecosystem integrity. Conservation Ecology (online) 1.

Green, D.G., Komp, N., Kimmington, G. \& Sadedin, S. (2006). Complexity in Landscape Ecology. Springer Landscape Series, Dodrecht, The Netherlands.

Green, J.L., Hastings, A., Arzberger, P., Ayala, F.J., Cottingham, K.L., Cuddington, K., Davis, F., Dunne, J.F., Fortin, M., Gerber, L. \& Neubert, M. (2005). Complexity in ecology and conservation: Mathematical, statistical, and computational challenges. BioScience 55:501-510. 
Forman, R.T.T, Godron, M. (1986). Landscape Ecology. Wiley and Sons, New York.

Forman, R. T. T. (1995). Land Mosaics. Cambridge University Press, New York.

Grossmann, W. D., Naveh Z. (2000). Transdisciplinary challenges for regional sustainable development toward the post-industrial information society. Proceedings of the Third International Conference of the European Society for Ecological Economics. May 3-6. Vienna. pp. 1-3.

Gunderson, L.H., Holling, C.S. (2002). Panarchy: Understanding Transformations in Human and Natural systems. Island Press, Washington, D.C.

Haber, W. (1990). Basic concepts of landscape ecology and their application in land management. Physiology and Ecology in Japan, 27:131-146.

Haber, W. (2004). The ecosystem- power of a metaphysical construct. Landschaftsoekolgie in Weihenstephan, Heft 13. Freising 2004:25-48.

Haken, H. (1987). Advanced Synergetics. Springer, Berlin.

Holling, C. S. (2000). Theories for sustainable futures. Conservation Ecology, 4: 7 (Editorial) Retrieved 2009, February, from http://www.concecol.org/vol4/iss2/art7

Jantsch, E.(1980). The Self-Organizing Universe. Scientific and Human Implications of the Emerging Paradigm of Evolution. Oxford: Pergamon Press.

Joergensen, S.E. (1997). Integration of Ecosystem Theories. A Pattern. Second revised edition. Dodrecht: Kluwer Academic Publishers.

Jorgensen, S. E., Muller, F. (2000). Handbook of Ecosystem Theories and Management. Lewis Publishers, Boca Raton.

Kuhn, T.S. (1970). The Structure of the Scientific Revolution. Chicago: University of Chicago Press.

Lange, E., Miller, D. (2005). Our shared landscape: integrating ecological, socio-economic and aesthetic aspects in landscape planning and management. Proceedings of a conference at Ascona, Switzerland, May 2-6 2005, Swiss Federal Institute of Technology, ITH Zurich.

Laszlo, E. (1987). Evolution: The Grand Synthesis. Shambala, New Science Library, Boston.

Laszlo, E. (1994). The Choice: Evolution or Extinction. A Thinking Person's Guide to Global Issues. New York: C. P. Putnam \& Sons.

Laszlo, E. (2002). The Connectivity Hypothesis. Foundations of an Integral Science of Quantum, Cosmos, Life, and Consciousness. Foreword by Ralph H. Abraham. State University of New York Press., New York.

Laszlo, E. (2004). Science and the Akashi Field An Integral Theory of Everything. Inner Traditions Rochester, Vermont.

Leser, H. (1999). Landschaftsoekologie. Eugen Ulmer,. Stuttgart.

Li, B.L. (2000). Why is the holistic approach becoming so important in landscape ecology? Landscape and Urban Planning, 50:27-47.

Li, B.L. (2001). Fuzzy statistical and modeling approach to ecological assessments. In: Jensen, M.E., Bourgeron, P.E. (Eds.): A Guidebook for Integrated Ecological Assessments. pp. 211-220. Springer-Verlag, New York.

Likens, G.E., Borman, F,H., Pierce, R.S. Eaton, J.S., \& Johnson, N.M. (1997). Biogeochemistry of a Forested Ecosystem. Springer, New York.

Lindeman, R.L. (1942). The trophic-dynamic aspect of ecology. Ecology, 23:399 
Loeffler, J. (2002). Landscape structures and processes. In: Bastian, O., Steinhardt, U. Development and Perspectives of Landscape Ecology. Kluwer Academic Publishers. Dodrecht, The Netherlands.

McDonnell, M.J., Pickett, S.T.A. (1993). Humans as Components of Ecosystems. The Ecology of Subtle Human Effects and Populated Areas. Springer New York, Berlin, Heidelberg:

Naveh, Z. (1971). Conservation of ecological diversity of Mediterranean ecosystems through ecological management. In: Duffy, E. \& Watt, A.S. (Eds.), The Scientific Management of Animal and Plant Communities for Conservation. 605-622 pp. Blackwell Sci. Publ., London

Naveh, Z. (1984). The vegetation of the Carmel and Nahal Sefunim and the evolution of the cultural landscape. In: Ronen, A. (Ed.) Sefunim Prehistoric Sites in Mount Carmel. pp. 23-63. B.A.R. International Series 230. Oxford

Naveh, Z. (1994). From Biodiversity to ecodiversity: a landscape-ecological approach to conservation and restoration. Restoration Ecology 2:180-189.

Naveh, Z. (1998a). From biodiversity to ecodiversity - holistic conservation of biological and cultural diversity of Mediterranean landscapes. In: Montenegro, G., Jaksic, F. \& Rundel, P.W. (Eds.). Landscape Disturbance and Biodiversity in Mediterranean-Type Ecosystems. pp. 23-54. Ecological Studies 136, Springer-Verlag Berlin Heidelberg

Naveh, Z. (1998b). Culture and landscape conservation: A landscape ecological perspective. In: Gopal, B. P., Pathak, P, Saxena, K. G. (Eds.) Ecology Today: An Anthology of Contemporary Ecological Research. International Scientific Publications, pp.19-48, New Delhi,

Naveh, Z. (2000). What is holistic landscape ecology? A conceptual introduction. Landscape and Urban Planning, 50, 7-26.

Naveh, Z. (2001). Ten major premises for a holistic conception of multifunctional landscapes. Landscape and Urban Planning 57:269-284.

Naveh, Z., Lieberman, A.S. (1994). Landscape Ecology Theory and Application. Second Edition. Springer, New York, Berlin, Heidelberg

Naveh, Z., Carmel, Y. (2003). The evolution of the cultural landscape in Israel as effected by fire, grazing, and human activities. In: Wasser, S.P. (Ed.), Papers in Honor of Eviatar Nevo. Evolutionary Theories and Processes. pp.397-401. Modern Horizons. Kluwer, Academic Publishers, Dodrecht

Naveh, Z. (2007a). The role of fire in the evolution of the Mediterranean cultural landscape in the Pleistocene and Early Holocene with special reference to Mt. Carmel. Transdisciplinary challenges in Landscape Ecology and Restoration Ecology - an Anthology. Springer Landscape Series. pp. 353-403.

Naveh, Z. (2007b). The transformation of landscape ecology and restoration ecology into transdisciplinary sciences of holistic landscape study, management, planning, conservation and restoration. Transdisciplinary Challenges in Landscape Ecology and Restoration Ecology - an Anthology. Springer, Landscape Series. pp. 353-403.

Noss, R. F. (2001). Maintaining ecological integrity of landscapes and eco- regions. In Noss, R. F. (Ed.): Ecological integrity: integrating environment, conservation, and health. p. 191-208. Island Press, Washington, D.C.

Odum, E.P. (1997). Fundamentals of Ecology. Third Edition. W.B. Saunders Company. Philadelphia.

Odum, E.P. (1993). Ecology and Our Endangered Life-Support Systems. Saunders Associated, Inc. Publishers, Sunderland, Massachusetts.

O’Neill, R. V., D. L. De Angelis, Waide, J.B. \& Allen, T. F. H. (1986). A hierarchical concept of ecosystems. Princeton University Press, Princeton, NJ. 
O'Neill, R.V. (2001). Is it time to bury the ecosystem concept? (with full military honors, of course!) Ecology, 82, 3275-3284.

Pacala, S.W., Canham, C.D. \& Silander, J. A. Jr. (1993). Forest models defined by field measurements: I. The design of a northeastern forest simulator. Canadian Journal of Forrest Research, 23(10): 1980-1988.

Palang, A., Soovali, H. Antrop, M. \& Setten, G. (2004). European Rural Landscapes: Persistence and Change in a Globalizing Environment. Kluwer Academic Publishers. Dodrecht/Boston/London.

Pickett, A., White, S.(1985). The ecology of Natural Disturbance and Patch Dynamic. New York: Academic Press.

Prigogine, I. (1976). Order through fluctuations: Self-organization and social systems. In Jantsch, E. (Ed.), Evolution and Consciousness: Human Systems in Transition, pp. 93-130. Waddington Reading Addison-Wesley, Massachusetts.

Prigogine, L. (1997). The End of Certainty: Time, Chaos, and the New Laws of Nature. The Free Press, New York.

Prigogine, I., Stengers, I.(1984). Order out of Chaos. Man's Dialogue with Nature. New Science Library Shamabala, Boston and London.

Risser, P.G. (1987). Landscape Ecology: State of the Art. In Turner, M.G. (Ed.), Landscape Heterogeneity and Disturbance. p. 314. Springer, New York,

Sagoff, M. (2001). Ecosystem design in historical and philosophical context. In Noss, R. F. W. (Ed.), Ecological integrity: integrating environment, conservation, and health. pp. 61-78. Island Press, Washington, D.C.

Schultz, A. M. (1967). The ecosystem as a conceptual tool in the management of natural resources. In: Cirancy-Wantrup, S.V., Parsons, J. J. (Eds.) Natural Resources: Quality and Quantity, pp.139-161. University Press, Berkeley,

Tansley, A.G. (1935). The use and abuse of vegetational concepts and terms. Ecology, 43:284307.

Turner, M.G., Gardner, R. \& O'Neil, R.V.O. (2001). Landscape Ecology in Theory and Practice. Pattern and Process. Springer, New York.

Troll, G. (1971). Landscape ecology (geo-ecology) and its bio-ceonology - a terminology study. Geoforum 8:43-46.

Weinberg, G. (1975). An Introduction to General Systems Thinking. Willey, New York.

Whittaker, R.H. (1975). Communities and Ecosystems. $2^{\text {nd }}$ edition Macmillan, New York.

World Resources 2000-2001 (2000). People and Ecosystems. The Fraying Web of Life. Amsterdam: Elsevier Science. Retrieved 2009, March, from htpp:Iwww.wli.org/wr2000.

Wu, J. (2007). Past, present and future of landscape ecology. Editorial. Landscape Ecology, 22:1433-1435.

Wu, J., Hobbs, R. (2002). Key issues and research priorities in landscape ecology: An idiosyncratic synthesis. Landscape Ecology, 17: 335-365.

Zonneveld, I.S. (1995). Land Ecology. An Introduction to Landscape Ecology as a Basis for Land Evaluation, Land Management and Conservation. SPB. Academic Publishing, Oxford. U.K. 